\title{
Efficacy and Safety of LAMA/LABA Fixed-Dose Combination Therapies in Chronic Obstructive Pulmonary Disease: A Systematic Review of Direct and Indirect Treatment Comparisons
}

This article was published in the following Dove Press journal:

International Journal of Chronic Obstructive Pulmonary Disease

John R Hurst'

Kevin Gruffydd-Jones $\mathbb{D}^{2}$

Mousumi Biswas $\mathbb{D}^{3}$

Deniz Guranlioglu ${ }^{4}$

Martin Jenkins ${ }^{4}$

Neda Stjepanovic $\mathbb{1}^{5}$

Arushi Bamrara $\mathbb{1}^{6}$

'UCL Respiratory, University College London, London, UK; ${ }^{2} \mathrm{GP}$, Box Surgery, Box, Wiltshire, UK; ${ }^{3}$ AstraZeneca, Gaithersburg, MD, USA; ${ }^{4}$ AstraZeneca, Cambridge, UK; ${ }^{5}$ AstraZeneca Gothenburg, Mölndal, Sweden; ${ }^{6}$ Parexel International, Punjab, India
Correspondence: John R Hurst Email j.hurst@ucl.ac.uk
Background: This literature review assessed comparative efficacy and safety of long-acting muscarinic antagonist/long-acting $\beta_{2}$-agonist (LAMA/LABA) fixed-dose combinations (FDCs) in patients with COPD and moderate-to-very severe airflow limitation, using evidence from direct (head-to-head) and indirect treatment comparisons.

Methods: Two systematic literature reviews were conducted to identify direct comparisons (head-to-head randomized controlled trials [RCTs]) and indirect comparisons (network metaanalyses [NMAs]; indirect treatment comparisons; meta-analyses) in patients with COPD with moderate-to-very severe airflow limitation. Study/Analysis characteristics, eligibility criteria, patient characteristics, and overall conclusions were extracted from relevant publications. The review of indirect comparisons focused on NMAs reporting efficacy outcomes at 12 and 24 weeks of treatment (established durations of symptomatic studies in COPD recommended by regulators). Results: Direct comparisons: Four RCTs that provided head-to-head comparisons of LAMA/ LABA FDCs were identified, and these varied in their study design, included patient population and reported endpoints. While some differences in lung function outcomes were noted, where assessed, LAMA/LABA FDCs had comparable efficacy in improving symptoms, health status, exacerbations, and comparable safety profiles. However, the differences in study methodology and patient characteristics between these studies made it difficult to draw generalizable conclusions regarding the comparative effectiveness of LAMA/LABA FDCs from the direct comparisons alone. Indirect comparisons: Six NMAs were identified that reported indirect comparisons between LAMA/ LABA FDCs; five of these were within the pre-defined scope of this review. Although the scope of each NMA varied, all five concluded that LAMA/LABA FDCs were generally comparable in terms of lung function improvements, patient-reported outcomes, and safety (where assessed).

Conclusion: Although there were some inconsistencies between the outcomes of RCTs and NMAs for lung function, the totality of lung function, symptoms, exacerbations, and safety data suggests that currently available LAMA/LABA FDCs have comparable efficacy and safety in patients with COPD and moderate-to-very severe airflow limitation.

Keywords: chronic obstructive pulmonary disease, direct evidence, indirect treatment comparisons, LAMA/LABA, efficacy, safety

\section{Plain Language Summary}

Bronchodilators are medicines given to patients with COPD to help them breathe more easily. Combining two bronchodilators in one inhaler (known as a long-acting muscarinic antagonist/long-acting $\beta_{2}$-agonist fixed-dose combination [LAMA/LABA FDC]) may be 
given to treat symptoms and stop flare-ups ('exacerbations') of COPD. Head-to-head clinical trials are the best way to compare two different drugs. However, there are not many head-to-head trials that have compared different LAMA/LABA FDCs. A network meta-analysis (NMA) is another way to compare two or more different drugs when head-to-head trials have not been done.

In this study, we looked for head-to-head trials and NMAs that compared different LAMA/LABA FDC drugs for people with moderate-to-very severe COPD. We found four head-tohead trials and six NMAs and compared their results.

In both the head-to-head trials and the NMAs, we found that the different LAMA/LABA FDCs were similar for improving symptoms of COPD, quality of life, and stopping flare-ups. They were also as safe to use as each other.

This study showed that, on the whole, different LAMA/ LABA FDCs work as well as each other and are as safe as each other.

\section{Introduction}

COPD is characterized by persistent respiratory symptoms and chronic airflow obstruction. It is a leading cause of global mortality and disability, ${ }^{1,2}$ and by 2030 , is predicted to be the third leading cause of death worldwide. ${ }^{3}$

The Global Initiative for Chronic Obstructive Lung Disease (GOLD 2020) recommends short- or long-acting bronchodilators as initial treatment for patients with COPD, depending on the individual patient's symptom burden and risk of future exacerbations. ${ }^{4}$ The combination of a long-acting muscarinic antagonist (LAMA) and longacting $\beta_{2}$-agonist (LABA) may be considered as an initial treatment option for patients with a high symptom burden or for treatment escalation in patients who experience persistent symptoms or exacerbations on monotherapy. ${ }^{4}$ In the GOLD 2020 report, LAMA/LABA combinations are considered as a class, and no distinctions are made between the available combinations.

LAMA/LABA combination therapy may be delivered via a separate inhaler for each bronchodilator component; however, the use of multiple inhalers can affect adherence and persistence to treatment, compared with the use of a single inhaler. ${ }^{5,6}$ Therefore, for convenience and to facilitate adherence to medication, several single-inhaler fixed-dose combinations (FDCs) have been developed. LAMA/LABA FDCs currently approved for maintenance treatment of COPD include umeclidinium/vilanterol, ${ }^{7}$ aclidinium/formoterol fumarate, ${ }^{8}$ and indacaterol/glycopyrrolate ${ }^{9}$ (all delivered via dry powder inhaler [DPI]), tiotropium/olodaterol soft mist inhaler (SMI), ${ }^{10}$ and glycopyrrolate/formoterol fumarate metered dose inhaler. ${ }^{11}$ The availability of different delivery devices allows treatment options to be matched to patient preferences, characteristics such as inspiratory flow, and device-handling experience. ${ }^{12}$

For physicians to make informed treatment choices to optimize the management of patients with COPD, it is important to have comparative evidence for the effectiveness of available treatment options. ${ }^{13}$ However, with the general absence of direct head-to-head comparisons, the use of network meta-analyses (NMA) can provide an indirect approach via a connected network that allows relative treatment effects to be estimated and outcomes across different trials to be assessed. ${ }^{13}$ As such, a more comprehensive body of evidence is then available by considering both direct and indirect comparisons. ${ }^{14}$

This literature review aimed to assess the comparative efficacy, in terms of lung function, exacerbations, and patient-reported outcomes (PROs), and safety of LAMA/ LABA FDCs in patients with COPD and moderate-to-very severe airflow limitation, using evidence from head-to-head studies and indirect treatment comparisons.

\section{Methods \\ Direct Evidence}

A systematic literature review was conducted to identify randomized controlled trials (RCTs) to evaluate direct evidence, which enrolled patients $\geq 40$ years of age with moderate-to-very severe airflow limitation. The systematic literature review was originally conducted with a broader objective and included studies with at least one LAMA/ LABA FDC or open LAMA + LABA treatment arm; however, only the studies reporting head-to-head comparisons of LAMA/LABA FDCs were included in the present review. Full details of the search strategy (including search terms) have been published previously. ${ }^{15}$ Databases evaluated included MEDLINE, MEDLINE In-Process, EMBASE, and the Cochrane Central Register of Controlled Trials (CENTRAL). Bibliographic screening of any relevant reviews published in the English language was conducted to validate the searches and ensure the inclusion of all relevant evidence. The databases were searched from their dates of inception to January 2020. Also, databases of abstracts presented between 2016 and January 2020 at the American Thoracic Society, European Respiratory Society, and American College of Chest Physicians annual conferences were hand-searched to retrieve studies not yet published in full-text articles or 
abstracts reporting supplementary results of previously published studies. Other sources included ClinicalTrials. gov, the International Clinical Trials Registry Platform, the Australian New Zealand Clinical Trials Registry, the GlaxoSmithKline Study Register, and company websites.

A first-stage screening process was conducted to review citations based on the article title and the abstract. Citations not matching the eligibility criteria were excluded at this stage, based on a pre-defined exclusion reason. Also, any duplicate citations were excluded. Two independent reviewers screened all citations, and a third independent reviewer resolved any discrepancies.

Following the completion of the first-stage screening, the full texts of relevant studies were retrieved and examined in more detail to determine a final list of included studies. Two independent reviewers screened the full-text articles, with any discrepancies resolved by a third independent reviewer.

For all relevant studies, details of the study characteristics, eligibility criteria, patient characteristics, and overall conclusions were extracted. To determine the risk of bias for each included RCT, the methodological quality of the study was assessed against a list of criteria relating to randomization and allocation concealment, baseline comparability, blinding, follow-up, selective reporting, and data analysis, including handling of missing data.

\section{Indirect Evidence}

A second literature search was performed to identify any indirect evidence. Eligible publications were systematic or targeted literature reviews with any quantitative analysis component, or meta-analyses, indirect treatment comparisons, or NMAs assessing comparative efficacy, safety and/or tolerability of LAMA/LABAs FDCs in patients with COPD with moderate-to-very severe airflow limitation. Only studies with full text in English were included. Analyses that were not based on RCTs were excluded from the review. The full search strategy (including search terms) is presented in the Supplementary Materials (Supplementary Table 1). Biomedical databases including MEDLINE, MEDLINE InProcess, EMBASE, and CENTRAL were reviewed, and bibliographic screening of relevant published reviews was conducted. The databases were searched from their date of inception to January 2020. Also, various Health Technology Assessment databases were searched, including the National Institute for Health and Care Excellence, the Scottish Medicines Consortium, the Canadian Agency for Drugs and Technologies in Health, the Pharmaceutical Benefits Advisory
Committee, the Institut für Qualität und Wirtschaftlichkeit im Gesundheitswesen, and Haute Autorité de Santé. Following an initial screen of retrieved citations by a single independent reviewer, a quality assessment of a $20 \%$ random sample was performed by a second independent reviewer. A first-stage screening process was conducted as described above for the direct evidence. Full texts of relevant studies were then retrieved to determine whether eligibility criteria of the literature review were met. For the current review, details of the characteristics of the analysis, eligibility criteria, patient characteristics, and overall conclusions were extracted. Also, details of any inconsistency testing conducted to assess whether there was any conflict between direct and indirect evidence were reviewed. The methodological quality (relevance and credibility) of all included indirect analyses was assessed using the International Society for Pharmacoeconomics and Outcomes Research consensusbased 26-item questionnaire. ${ }^{16}$

The final review focused on NMAs that reported efficacy outcomes at 12 and 24 weeks of treatment, established durations of symptomatic studies in COPD recommended by regulators. $^{17}$

\section{Results}

\section{Direct Evidence: Study Characteristics}

Using the results of the systematic literature review, four RCTs from three publications were identified that provided head-to-head comparison of LAMA/LABA FDCs in patients with moderate-to-very severe airflow limitation in COPD (Figure 1): the AERISTO study, a 24-week, multicenter, international, Phase IIIb, double-blind study; ${ }^{18}$ Study A2349 and Study A2350, two identically designed 12-week, multicenter, US, Phase III, doubleblind studies; ${ }^{19}$ and Study GSK204990, an 8-week, multicenter, international, Phase IV, open-label study. ${ }^{20}$

In terms of the characteristics of the studies identified in the literature search, some differences were noted across the studies in treatment duration, study design (parallelgroup vs the crossover), the number of patients randomized, and levels of blinding (Table 1). All four RCTs included umeclidinium/vilanterol DPI as one of the study treatments; this was compared with glycopyrrolate/formoterol fumarate pressurized metered dose inhaler in one study (AERISTO), indacaterol/glycopyrrolate DPI in two studies (Study A2349 and Study A2350), and tiotropium/ olodaterol SMI in one study (Study GSK204990). 
Table I Study Design and Patient Characteristics of Head-to-Head Comparison Studies

\begin{tabular}{|c|c|c|c|c|}
\hline & AERISTO Study ${ }^{18}$ & Study A2349 ${ }^{19}$ & Study A2350 ${ }^{19}$ & $\begin{array}{l}\text { Study } \\
\text { GSK204990 }\end{array}$ \\
\hline \multicolumn{5}{|l|}{ Study design } \\
\hline $\begin{array}{l}\text { ClinicalTrials.gov } \\
\text { identifier }\end{array}$ & NCT03।62055 & NCT02487446 & NCT02487498 & NCT02799784 \\
\hline $\begin{array}{l}\text { No. of randomized } \\
\text { patients }\end{array}$ & 1119 & 357 & 355 & 236 \\
\hline Publication type & Primary manuscript & Primary manuscript & Primary manuscript & Primary manuscript \\
\hline Study design & Parallel-group & Crossover & Crossover & Crossover \\
\hline $\begin{array}{l}\text { Treatment } \\
\text { duration (weeks) }\end{array}$ & 24 & 12 & 12 & 8 \\
\hline Blinding & Double-blind & Double-blind & Double-blind & Open-label \\
\hline Setting & $\begin{array}{l}\text { Multicenter, international (Bulgaria, } \\
\text { Canada, France, Hungary, Russia, } \\
\text { Ukraine, USA) }\end{array}$ & Multicenter; USA ${ }^{\mathrm{a}}$ & Multicenter; USA ${ }^{\mathrm{a}}$ & $\begin{array}{l}\text { Multicenter } \\
\text { international; } \\
\text { (Germany, Spain, UK, } \\
\text { USA) }\end{array}$ \\
\hline $\begin{array}{l}\text { Intervention vs } \\
\text { comparators }\end{array}$ & $\begin{array}{l}\text { GLY/FOR pressurized MDI I 8/9.6 } \mu \mathrm{g} \\
\text { BID vs UMEC/VIL DPI } 62.5 / 25 \mu \mathrm{g} \text { OD }\end{array}$ & $\begin{array}{l}\text { GLY/IND DPI I } 5.6 / 27.5 \mu \mathrm{g} \\
\text { BID vs UMEC/VIL DPI } 62.5 / \\
25 \mu \mathrm{g} \text { OD }\end{array}$ & $\begin{array}{l}\text { GLY/IND DPI I } 5.6 / 27.5 \mu \mathrm{g} \\
\text { BID vs UMEC/VIL DPI } 62.5 / \\
25 \mu \mathrm{g} \text { OD }\end{array}$ & $\begin{array}{l}\text { UMEC/VIL DPI } \\
62.5 / 25 \mu \mathrm{g} \text { OD vs TIO/ } \\
\text { OLO SMI 5/5 } \mu \mathrm{g} \text { OD }\end{array}$ \\
\hline COPD severity & Moderate-to-very severe & Moderate-to-severe & Moderate-to-severe & Moderate \\
\hline \multicolumn{5}{|c|}{ Patient characteristics at baseline } \\
\hline Mean age, years & 64.1 & 64.1 & 63.9 & 64.4 \\
\hline Male, \% & 72.6 & 52.1 & 54.1 & 60.0 \\
\hline $\begin{array}{l}\text { Current } \\
\text { smoker, \% }\end{array}$ & 53.5 & 56.9 & 57.2 & 53.0 \\
\hline $\begin{array}{l}\text { Mean post- } \\
\text { bronchodilator } \\
\mathrm{FEV}_{1}, \% \text { predicted }\end{array}$ & 48.7 & 54.0 & 54.6 & 59.6 \\
\hline Severe COPD, \% & 48.0 & 35.6 & 37.5 & NA \\
\hline $\begin{array}{l}\geq 1 \text { exacerbation } \\
\text { in the } \\
\text { previous year, \% }\end{array}$ & 47.9 & 22.1 & 26.2 & 22.0 \\
\hline
\end{tabular}

Notes: All studies had adequate methods of randomization. ${ }^{a}$ Identified from ClinicalTrials.gov.

Abbreviations: BID, twice daily; FEV , forced expiratory volume in I second; FOR, formoterol fumarate; GLY, glycopyrrolate; IND, indacaterol; MDI, metered dose inhaler; NA, not applicable; NR, not reported; OD, once daily; OLO, olodaterol; TIO, tiotropium; VIL, vilanterol; UMEC, umeclidinium.

Differences in inclusion criteria for airflow limitation were noted, with the AERISTO study including patients with moderate-to-very severe airflow obstruction; Study A2349 and Study A2350 including patients with moderateto-severe airflow obstruction; and Study GSK204990 including only patients with moderate airflow obstruction. The outcomes assessed across the studies also varied. All four studies evaluated changes in lung function as the primary endpoint, although the specific outcomes and timepoints assessed differed across the studies. PROs evaluated included Transition Dyspnea Index (TDI) focal score, COPD Assessment Test (CAT) score, and Evaluating

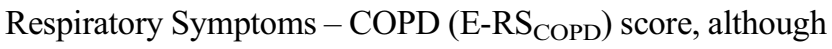
these were not reported consistently across all four studies. 


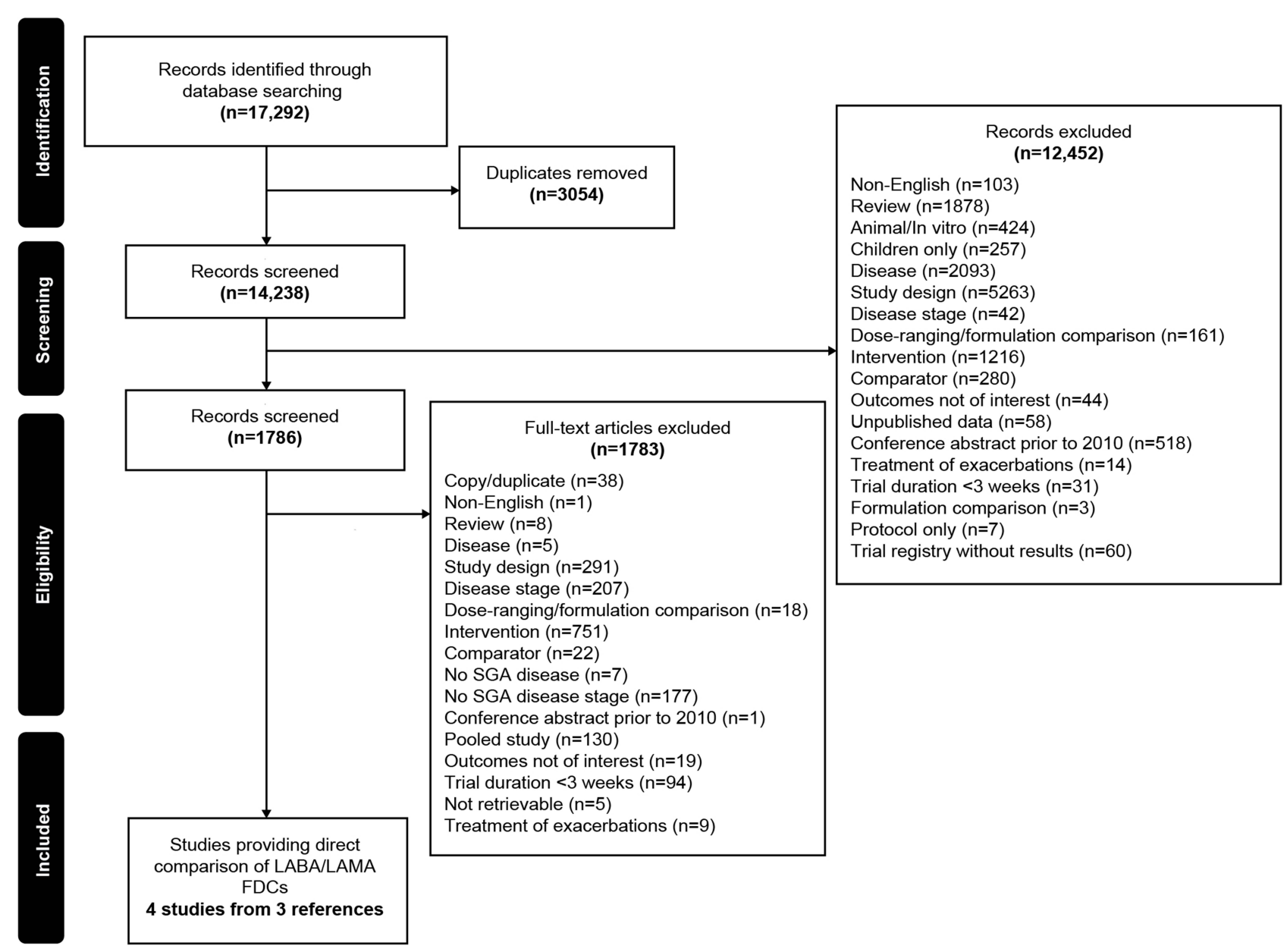

Figure I Flow of head-to-head comparative studies through the systematic review process.

Abbreviations: CSR, clinical study report; FDC, fixed-dose combination; LABA, long-acting $\beta_{2}$-agonist; LAMA, long-acting muscarinic antagonist; SGA, subgroup analyses.

None of the studies evaluated quality of life using the St. George's Respiratory Questionnaire (SGRQ). Only the AERISTO study evaluated exacerbations as an efficacy outcome, and only in an exploratory analysis.

Moreover, patient baseline characteristics varied across trials (Table 1). In line with the differences in inclusion criteria, the mean percentage predicted post-bronchodilator forced expiratory volume in 1 second $\left(\mathrm{FEV}_{1}\right)$ at baseline was highest in Study GSK204990 (59.6\%) and lowest in the AERISTO study (48.7\%). The proportion of patients with at least one exacerbation in the previous year was almost 2-fold higher in the AERISTO study (47.9\%) compared with Study A2350 (26.2\%) and Study A2349 (22.1\%).

The risk of bias was low in the AERISTO study, Study A2349, and Study A2350, whereas Study GSK204990 was associated with a high risk of bias because of the open-label nature and analysis of the primary efficacy endpoint in the per-protocol population. Also, baseline characteristics were well-balanced across the randomized treatment arms in three studies (AERISTO, Study A2349, and Study A2350), while this information was unclear in Study GSK204990.

\section{Direct Evidence: Lung Function}

The co-primary outcomes evaluated in the AERISTO trial were change from baseline in morning pre-dose trough $\mathrm{FEV}_{1}$ over 24 weeks and peak change from baseline in $\mathrm{FEV}_{1}$ within 2 hours post-dosing over 24 weeks (Table 2). Non-inferiority for glycopyrrolate/formoterol fumarate versus umeclidinium/vilanterol was demonstrated for change from baseline in peak $\mathrm{FEV}_{1}$ within 2 hours post-dose over 24 weeks (demonstrated by the lower bound of the 2-sided 97.5\% confidence interval [CI] of the least squares means [LSM] difference greater than the pre-determined margin of $50 \mathrm{~mL}$ ), but not for change from baseline in morning pre-dose trough $\mathrm{FEV}_{1}$ over 24 weeks.

The primary endpoint in Study A2349 and Study A2350 was change from baseline in $\mathrm{FEV}_{1}$ area under the plasma 
Table 2 Primary Lung Function Endpoints in Head-to-Head RCTs

\begin{tabular}{|c|c|c|c|c|}
\hline Outcomes & AERISTO Study ${ }^{18}$ & Study A2349 ${ }^{19}$ & Study A2350 ${ }^{19}$ & Study GSK20499020 \\
\hline $\begin{array}{l}\text { Intervention vs } \\
\text { comparators }\end{array}$ & $\begin{array}{l}\text { GLY/FOR I8/9.6 } \mu \mathrm{g} \text { BID vs } \\
\text { UMEC/VIL } 62.5 / 25 \mu \mathrm{g} \text { OD }\end{array}$ & $\begin{array}{l}\text { GLY/IND I5.6/27.5 } \mu \mathrm{g} \text { BID } \\
\text { vs UMEC/VIL } 62.5 / 25 \mu \mathrm{g} \\
\text { OD }\end{array}$ & $\begin{array}{l}\text { GLY/IND I5.6/27.5 } \mu \mathrm{g} \\
\text { BID vs UMEC/VIL } 62.5 / 25 \\
\mu \mathrm{g} \text { OD }\end{array}$ & $\begin{array}{l}\text { UMEC/VIL 62.5/25 } \mu \mathrm{g} \text { OD } \\
\text { vs TIO/OLO 5/5 } \mu \mathrm{g} \text { OD }\end{array}$ \\
\hline \multirow[t]{2}{*}{$\begin{array}{l}\text { Trough FEV } \\
\text { Mean (SE) } \\
\text { change from } \\
\text { baseline, } \mathrm{mL} \\
\text { Treatment } \\
\text { difference, } \mathrm{mL} \\
{[\mathrm{Cl}]}\end{array}$} & \multirow[t]{2}{*}{$\begin{array}{l}\text { GLY/FOR: } 82.4 \text { (I I .2) } \\
\text { UMEC/VIL: } 169.6 \text { (I I.2) } \\
-87.2 \\
{[97.5 \% \mathrm{Cl}=-1 / 7 .} \\
0,-57.4] \\
\mathrm{NI} \text { of GLY/FOR not } \\
\text { demonstrated over } 24 \text { weeks } \\
(\mathrm{NI} \text { margin }-50 \mathrm{~mL})^{\mathrm{a}}\end{array}$} & \multirow[t]{2}{*}{ NA } & \multirow[t]{2}{*}{ NA } & $\begin{array}{l}\mathrm{NI} \text { analysis (PP population) } \\
\text { UMEC/VIL: I } 75.0(13.0) \\
\text { TIO/OLO: I } 22.0(14.0) \\
53.0 \\
{[95 \% \mathrm{CI}=26,80]} \\
\mathrm{NI} \text { of UMEC/VIL demonstrated } \\
\text { over } 8 \text { weeks (NI margin }-50 \mathrm{~mL})\end{array}$ \\
\hline & & & & $\begin{array}{l}\text { Subsequent superiority analysis } \\
\text { (ITT population) } \\
\text { UMEC/VIL: I } 80.0(13.0) \\
\text { TIO/OLO: } 128.0(13.0) \\
52.0 \\
{[95 \% \mathrm{Cl}=28,77]} \\
\text { Superiority of UMEC/VIL } \\
\text { demonstrated over } \\
8 \text { weeks (superiority defined as } \\
\text { lower bound of } 95 \% \mathrm{Cl} \text { for the } \\
\text { treatment difference }>0 \text { ) }\end{array}$ \\
\hline \multirow[t]{2}{*}{$\begin{array}{l}\text { Peak FEV }{ }_{1}{ }^{b} \\
\text { Mean (SE), } \mathrm{mL} \\
\text { Treatment } \\
\text { difference, } \mathrm{mL} \\
{[\mathrm{Cl}]}\end{array}$} & $\begin{array}{l}\text { GLY/FOR: } 293.5(10.2) \\
\text { UMEC/VIL: } 296.9(10.3) \\
-3.4 \\
\text { [97.5\% Cl: }-32.8,25.9] \\
\text { NI of GLY/FOR demonstrated } \\
\text { over } \\
24 \text { weeks (NI margin - } \\
50 \mathrm{~mL})^{\mathrm{a}}\end{array}$ & \multirow[t]{2}{*}{ NA } & \multirow[t]{2}{*}{ NA } & \multirow[t]{2}{*}{ NA } \\
\hline & $\begin{array}{l}\text { Superiority not demonstrated } \\
\text { over } 24 \text { weeks }\end{array}$ & & & \\
\hline $\begin{array}{l}\mathrm{FEV}_{\mathrm{I}} \mathrm{AUC}_{0-24 \mathrm{~h}} \\
\text { Mean (SE) } \\
\text { change from } \\
\text { baseline, } \mathrm{mL} \\
\text { Treatment } \\
\text { difference, } \mathrm{mL} \\
{[\mathrm{Cl}]}\end{array}$ & NA & $\begin{array}{l}\text { GLY/IND: } 232.1(\text { (I I.3) } \\
\text { UMEC/VIL: } 243.6 \\
(1 \mathrm{I} .3)-1 \mathrm{I} .5 \\
{[95 \% \mathrm{Cl}=-26.9,3.8]} \\
\mathrm{NI} \text { of GLY/IND not } \\
\text { demonstrated at Week } 12 \\
(\mathrm{NI} \text { margin }-20 \mathrm{~mL})\end{array}$ & $\begin{array}{l}\text { GLY/IND: } 184.6(\text { II.9) } \\
\text { UMEC/VIL: } 202.8 \\
(I I .9)-18.2 \\
\text { [95\% Cl = -34.2, -2.3] } \\
\mathrm{NI} \text { of GLY/IND not } \\
\text { demonstrated at Week } 12 \\
\text { (NI margin }-20 \mathrm{~mL} \text { ) }\end{array}$ & NA \\
\hline
\end{tabular}

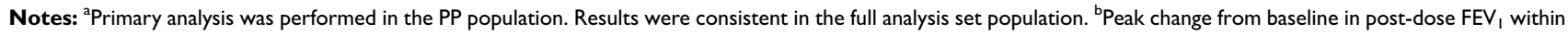
$2 \mathrm{~h}$ post-dose. Light gray shading, primary objective met; dark gray shading, primary objective not met.

Abbreviations: $\mathrm{AUC}_{0-24 \mathrm{~h}}$, area under the plasma concentration-time curve from 0 to 24 hours; $\mathrm{BID}$, twice daily; $\mathrm{Cl}$, confidence interval; $\mathrm{FEV}, \mathrm{f}$, forced expiratory volume in I second; FOR, formoterol fumarate; GLY, glycopyrrolate; IND, indacaterol; ITT, intent-to-treat; NA, not applicable; NI, non-inferiority; OD, once daily; OLO, olodaterol; PP, per protocol; RCT, randomized controlled trial; SE, standard error; TIO, tiotropium; UMEC, umeclidinium; VIL, vilanterol.

concentration-time curve from 0 to 24 hours $\left(\mathrm{AUC}_{0-24 \mathrm{~h}}\right)$ at Week 12. In both trials, the non-inferiority of indacaterol/glycopyrrolate relative to umeclidinium/vilanterol (demonstrated by the lower bound of the 1-sided 97.5\% CI of the LSM difference relative to the pre-determined margin of $-20 \mathrm{~mL}$ ) was not met (Table 2). 
In Study GSK204990, the primary endpoint was change from baseline in trough $\mathrm{FEV}_{1}$ at Week 8. Umeclidinium/ vilanterol was non-inferior to tiotropium/olodaterol (demonstrated by the lower bound of the 2-sided $95 \%$ CI of the LSM difference greater than the pre-specified margin of $-50 \mathrm{~mL}$; per-protocol population; Table 2); a subsequent analysis in the intent-to-treat population demonstrated that umeclidinium/vilanterol was superior to tiotropium/olodaterol (lower bound of the $95 \%$ CI for the treatment difference $>0 \mathrm{~mL}$; Table 2).

Data for secondary lung function endpoints (trough $\mathrm{FEV}_{1}$, trough $\mathrm{FEV}_{1}$ responders, $\mathrm{FEV}_{1}$ area under the plasma concentration-time curve from 0 to 12 hours $\left[\mathrm{AUC}_{0-12 \mathrm{~h}}\right], \mathrm{FEV}_{1}$ area under the plasma concentrationtime curve from 12-24 hours $\left[\mathrm{AUC}_{12-24 \mathrm{~h}}\right]$, trough forced vital capacity [FVC], trough inspiratory capacity [IC], and post-dose peak IC) are presented in the Supplementary Materials (Supplementary Table 2). In contrast, no lung function endpoints other than trough $\mathrm{FEV}_{1}$, peak $\mathrm{FEV}_{1}$ and $\mathrm{FEV}_{1}$ area under the plasma concentration-time curve from 0 to 4 hours $\left(\mathrm{AUC}_{0-4}\right)$ were evaluated in NMAs (see "Indirect evidence: Lung function" section).

\section{Direct Evidence: PROs}

In the AERISTO study, the PROs evaluated included changes from baseline in TDI focal score and CAT scores over 24 weeks (Supplementary Table 3). Nominal noninferiority of glycopyrrolate/formoterol fumarate versus umeclidinium/vilanterol was established for both outcomes, according to the pre-specified non-inferiority margins. Study GSK204990 evaluated change from baseline in CAT scores and E-RS ${ }_{\text {COPD }}$ scores (Supplementary Table 3). No difference between treatments was observed in change from baseline in CAT scores or E-RS $\mathrm{COPD}_{\mathrm{C}}$ scores at Week 8 between umeclidinium/vilanterol and tiotropium/olodaterol. PROs were not analyzed formally in Study A2349 and Study A2350.

\section{Direct Evidence: Exacerbations}

Time to first moderate-to-severe COPD exacerbation was evaluated as an exploratory secondary efficacy endpoint in the AERISTO study only. During the 24-week treatment period, the effect of glycopyrrolate/formoterol fumarate and umeclidinium/vilanterol on time to first moderate-tosevere exacerbation was comparable, with a hazard ratio close to 1 (hazard ratio $=0.97 ; 95 \% \mathrm{CI}=0.73-1.29$ ).

\section{Direct Evidence: Safety}

The results of all four head-to-head RCTs suggested that the proportion of patients reporting any adverse events (AEs) was similar between LAMA/LABA treatment groups in each study (AERISTO: glycopyrrolate/formoterol fumarate 40.9\%; umeclidinium/vilanterol 44.9\%; Study A2349: indacaterol/glycopyrrolate $41.3 \%$; umeclidinium/vilanterol $44.1 \%$; Study A2350: indacaterol/glycopyrrolate $35.0 \%$; umeclidinium/vilanterol 34.6\%; Study GSK204990: tiotropium/olodaterol 31\%; umeclidinium/vilanterol $25 \%$ ). Also, where reported, the proportions of patients reporting serious AEs, treatment-related AEs, or AEs leading to discontinuation were similar between LAMA/LABA FDCs in each study.

\section{Indirect Evidence: Study Characteristics}

Following the literature review, a total of six NMAs were identified that provided indirect comparisons of LAMA/ LABA FDCs (Figure 2); however, one of these was out of the pre-defined scope of this review as it included studies of short duration ( 3 and 6 weeks) and did not specifically report outcomes at or over 12 or 24 weeks. ${ }^{21}$ All NMAs included RCTs conducted in adult patients with stable, moderate-to-very severe airflow obstruction, ${ }^{15,22-25}$ The NMA by Aziz et al included only parallel-group RCTs. ${ }^{22}$ The NMAs by Siddiqui et $\mathrm{al}^{15}{ }^{15}$ Sion et $\mathrm{al},{ }^{23}$ Schlueter et $\mathrm{al}^{24}$ and Huisman et $\mathrm{al}^{25}$ did not have any restriction on the design of the RCTs as both cross-over and parallel studies were included (Table 3).

The scope of each NMA varied (Table 3). For example, the NMAs by Aziz et al, ${ }^{22}$ Sion et $\mathrm{al}^{23}$ and Huisman et $\mathrm{al}^{25}$ included RCTs with durations of $\geq 8$ weeks, $\geq 10$ weeks, and $\geq 12$ weeks, respectively, whereas the NMA by Schlueter et $\mathrm{al}^{24}$ had no restrictions on the duration of the RCTs but only included those reporting outcomes of interest at 20-28 weeks and 48-52 weeks. Three of the NMAs compared several classes of inhalation therapy, including LAMA/ LABA (FDCs and open combinations), inhaled corticosteroid (ICS)/LABA (FDCs and open combinations), and LAMA monotherapy, whereas the Siddiqui et $\mathrm{al}^{15}$ and Schleuter et al ${ }^{24}$ NMAs focused on the comparative efficacy of LAMA/LABA FDCs. The most recently published NMAs included a wider variety of LAMA/LABA FDCs compared with earlier NMA publications, due to the availability of new combinations. In four NMAs, the comparators of interest were any of the listed interventions and placebo, whereas in the NMA by Siddiqui et al, ${ }^{15}$ only RCTs evaluating LAMA/ LABA FDCs were included. 


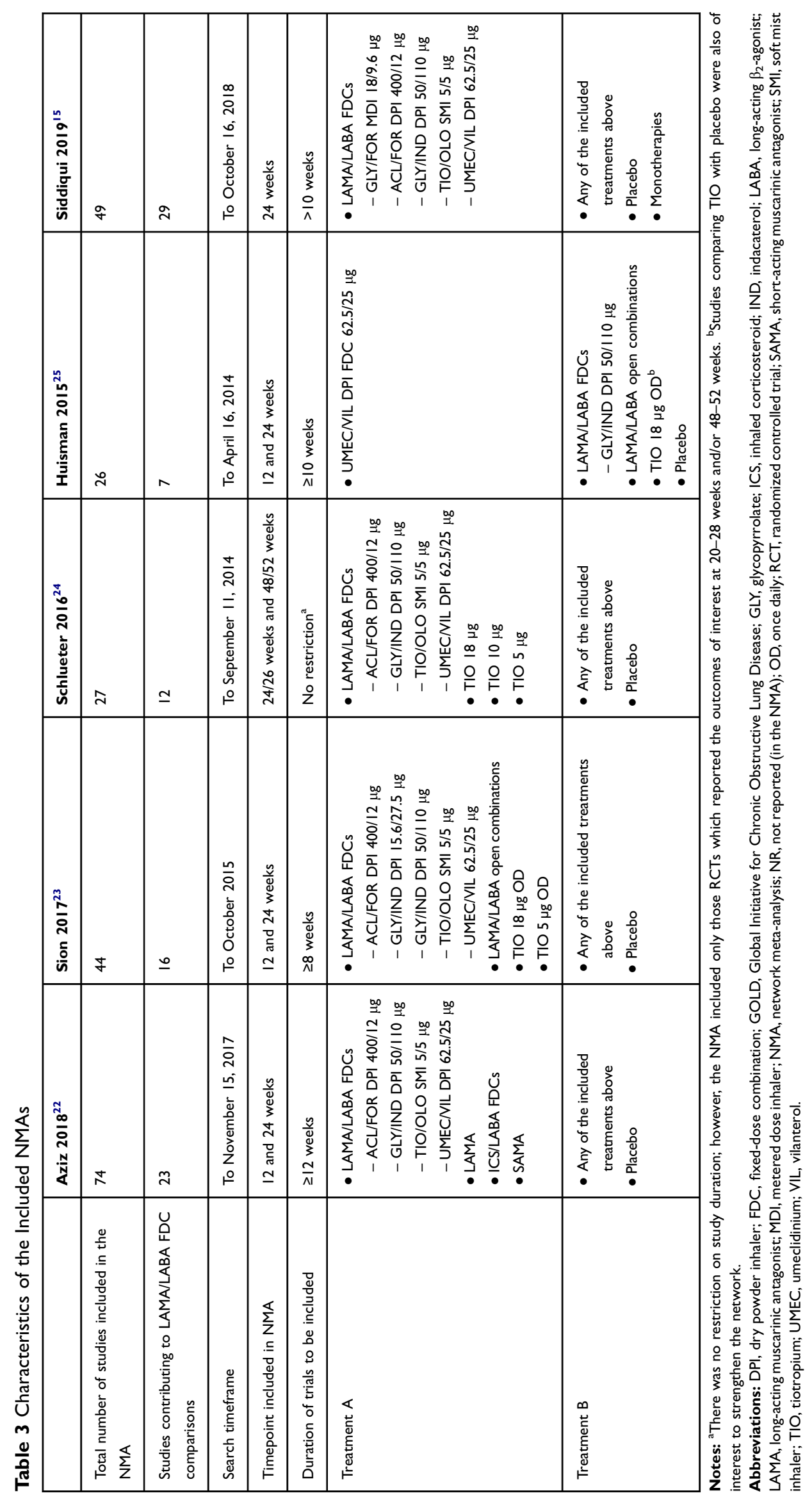




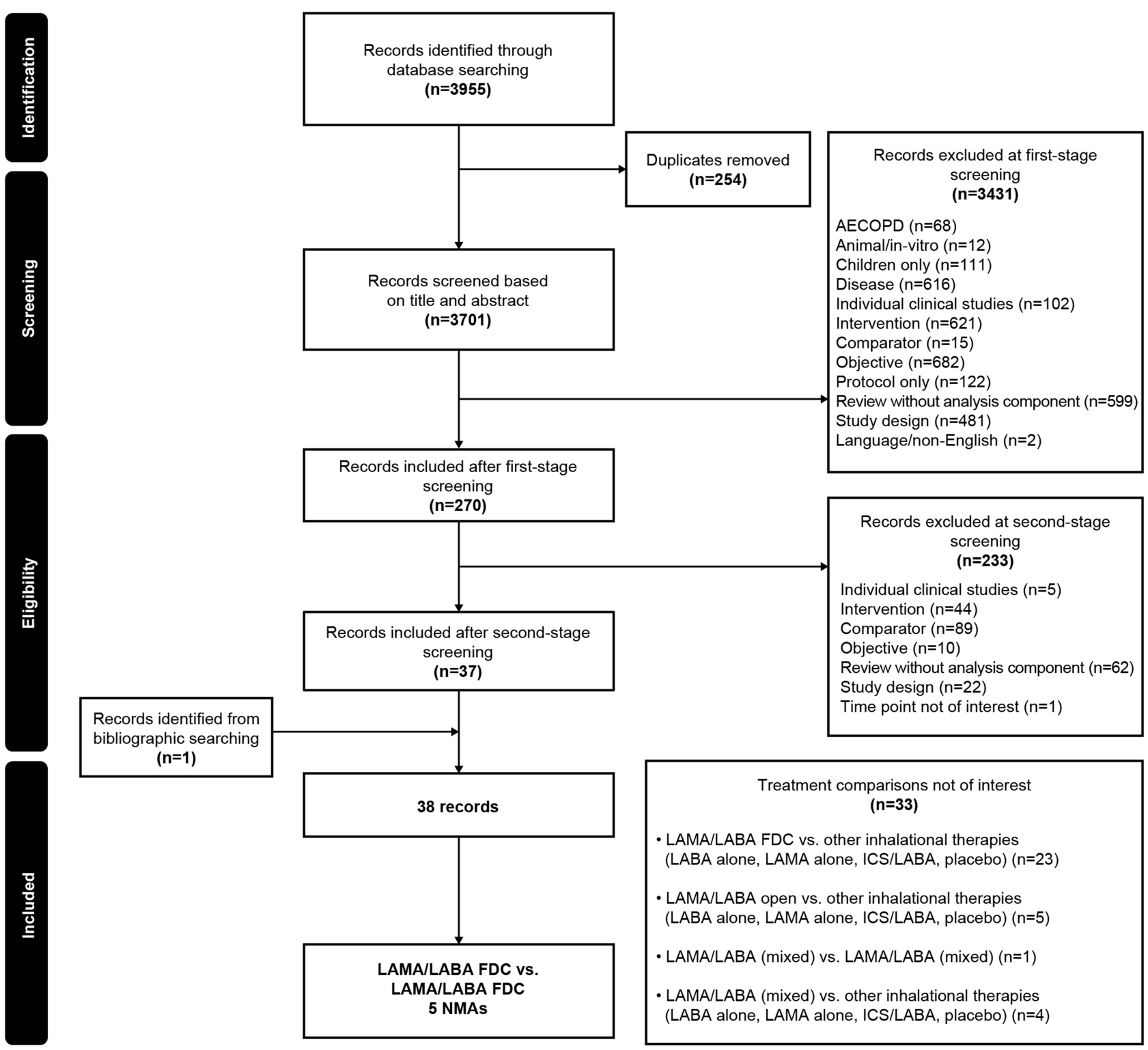

Figure 2 Flow of NMA studies through the systematic review process.

Abbreviations: AECOPD, acute exacerbations of chronic obstructive pulmonary disease; FDC, fixed-dose combination; ICS, inhaled corticosteroid; LABA, long-acting $\beta_{2}$-agonist; LAMA, long-acting muscarinic antagonist; NMA, network meta-analysis.

\section{Indirect Evidence: Quality Assessment}

Results of the quality assessment demonstrated that all NMAs included populations and interventions relevant to their research objective, and identified RCTs using a comprehensive systematic literature review. Peak $\mathrm{FEV}_{1}, \mathrm{FEV}_{1} \mathrm{AUC}_{0-4 \mathrm{~h}}$, and exacerbation endpoints were generally absent from the outcomes evaluated in the NMAs, except for the Siddiqui et $\mathrm{al}^{15}$ NMA. A connected network of RCTs was formed in each of the published NMAs and included both direct and indirect comparisons. Of note, all NMAs included studies associated with a high risk of bias; these studies were either open-label or the method of randomization (or available description of the method of randomization) was not considered adequate.

All of the NMAs attempted to identify treatment effect modifiers (ie, patient characteristics that may impact the effectiveness of treatment) across the included RCTs, and three NMAs (Siddiqui et al, ${ }^{15}$ Sion et $a{ }^{23},{ }^{23}$ and Schlueter et $\mathrm{al}^{24}$ ) reported differences in the distribution of treatment effect modifiers across studies. Schlueter et $\mathrm{al}^{24}$ performed meta-regression to adjust for baseline disease severity and 
concomitant ICS use, whereas Sion et $\mathrm{al}^{23}$ performed subgroup analyses to control for severity of lung function impairment and baseline ICS use. Siddiqui et al ${ }^{15}$ conducted a meta-regression analysis to account for differences in baseline airflow limitation, SGRQ total score, and ICS use. Also, a subgroup analysis in symptomatic patients was performed for symptoms, quality of life, and exacerbation endpoints. From the quality assessment, the conclusions in each NMA were considered fair and balanced.

\section{Indirect Evidence: Heterogeneity and Inconsistency}

All NMAs discussed heterogeneity across the included RCTs with respect to study characteristics and patient baseline characteristics. Overall, the RCTs included in these NMAs were comparable in terms of study characteristics; however, some variations in patient sample sizes were observed. Across the NMAs, heterogeneity was observed for COPD severity, mean percentage predicted $\mathrm{FEV}_{1}$ at baseline, exacerbation history in the previous year, smoking status, concomitant ICS at baseline, mean SGRQ score at baseline, and gender.

Aziz et $\mathrm{al}^{22}$ did not find any inconsistency in the networks of any of the outcomes analyzed. Schlueter et $\mathrm{al}^{24}$ identified a potential inconsistency in the network of change from baseline in SGRQ score at 24/26 weeks, caused by two umeclidinium/vilanterol trials in which the direction of results was different. However, no explanation could be provided for this difference, because COPD severity and concomitant medication use - factors that could potentially contribute to differences in treatment effects - were similar in both trials. Siddiqui et al ${ }^{15}$ identified potential inconsistencies in the networks of TDI responders at 24 weeks for the comparison of glycopyrrolate/formoterol fumarate versus umeclidinium/vilanterol. There was also a potential inconsistency between direct and indirect evidence for trough $\mathrm{FEV}_{1}$, which may reflect the differential results observed in the direct evidence (AERISTO study; note that this study was only included in the Siddiqui et $\mathrm{al}^{15} \mathrm{NMA}$ due to its more recent search timeframe).

\section{Indirect Evidence: Lung Function}

Only trough $\mathrm{FEV}_{1}$, peak $\mathrm{FEV}_{1}$ and $\mathrm{FEV}_{1} \mathrm{AUC}_{0-4}$ were evaluated in NMAs; therefore, the results of the other lung function endpoints are not discussed. All five of the included NMAs evaluated change from baseline in trough
$\mathrm{FEV}_{1}$ as an outcome. In general, the LAMA/LABA FDCs appeared comparable with each other in improving change from baseline in trough $\mathrm{FEV}_{1}$ at 24/26 weeks (Table 4 and Supplementary Table 4). Results for change from baseline in trough $\mathrm{FEV}_{1}$ at 24/26 weeks were inconsistent between the NMAs specifically for the comparison of aclidinium/ formoterol fumarate with the other FDCs of glycopyrrolate/indacaterol, tiotropium/olodaterol, and umeclidinium/ vilanterol, with some comparisons reaching statistical significance (Table 4).

Change from baseline in peak $\mathrm{FEV}_{1}$ and $\mathrm{FEV}_{1}$ $\mathrm{AUC}_{0-4 \mathrm{~h}}$ were only evaluated in the Siddiqui et al NMA. At 24 weeks, the magnitude of the effect of the change from baseline in peak $\mathrm{FEV}_{1}$ was generally comparable between the LAMA/LABA FDCs; however, a statistically significant difference in favor of glycopyrrolate/formoterol fumarate versus umeclidinium/vilanterol was seen (Supplementary Table 5). With respect to change from baseline in $\mathrm{FEV}_{1} \mathrm{AUC}_{0-4 \mathrm{~h}}$ at 24 weeks, all LAMA/ LABA FDCs appeared comparable, with mean treatment differences being statistically non-significant for each comparison (range $-5.2 \mathrm{~mL}$ with umeclidinium/vilanterol vs glycopyrrolate/indacaterol to $4.6 \mathrm{~mL}$ with glycopyrrolate/indacaterol vs glycopyrrolate/formoterol fumarate; Supplementary Table 6).

\section{Indirect Evidence: PROs}

TDI focal score and changes from baseline in SGRQ scores at 24/26 weeks were analyzed in all five included NMAs (Supplementary Tables 7 and $\underline{8}$ ), ${ }^{15,22-25}$ and the proportions of TDI and SGRQ responders at 24/26 weeks ${ }^{15,22,24}$ were analyzed in three NMAs (Supplementary Tables 9 and $\underline{10}$ ). The LAMA/LABA FDCs analyzed were all comparable in relation to improvements in these endpoints (Supplementary Tables 7-14).

\section{Indirect Evidence: Exacerbations}

Of the five included NMAs identified in the literature review, only the Schlueter et $\mathrm{al}^{24}$ and Siddiqui et $\mathrm{al}^{15}$ NMAs evaluated rates of moderate-to-severe COPD exacerbations (Supplementary Tables 15 and $\underline{16}$ ). No statistically significant differences were observed between glycopyrrolate/formoterol fumarate, glycopyrrolate/indacaterol, tiotropium/olodaterol, and umeclidinium/vilanterol in terms of reduction in the rate of moderate-to-severe exacerbations. 
Table 4 NMA Results for Change from Baseline in Trough FEV , at 24/26 Weeks for Each Treatment Comparison by Study ${ }^{\mathrm{a}}$

\begin{tabular}{|c|c|c|c|c|}
\hline \multirow[t]{2}{*}{ Treatment A } & \multicolumn{4}{|l|}{ Treatment B } \\
\hline & ACL/FOR 400/12 $\mu \mathrm{g}$ BID & GLY/FOR I8/9.6 $\mu \mathrm{g}$ BID & GLY/IND 50/1 $10 \mu \mathrm{g}$ OD & TIO/OLO 5/5 $\mu \mathrm{g}$ OD \\
\hline $\begin{array}{l}\text { ACL/FOR 400/12 } \mu \mathrm{g} \\
\text { BID }\end{array}$ & - & - & - & - \\
\hline $\begin{array}{l}\text { GLY/FOR I8/9.6 } \mu \mathrm{g} \\
\text { BID }\end{array}$ & $\begin{array}{l}\leftrightarrow \\
\text { Siddiqui 2019: } 0.4(-25.6,26.3)\end{array}$ & - & - & - \\
\hline \multirow[t]{2}{*}{$\begin{array}{l}\text { GLY/IND 50/I10 } \mu \mathrm{g} \\
\text { OD }\end{array}$} & $\begin{array}{l}\uparrow \\
\text { Aziz 20।8: } 43.5(8.1,78.8) \\
\text { Schlueter } 2016 \text { FEM: } 42(7,77) \\
\text { Sion 20I7: } 43.6(15.7,71.4)\end{array}$ & \multirow[t]{2}{*}{$\begin{array}{l}\leftrightarrow \\
\text { Siddiqui 2019: } 23.0(-5.9,66.8)\end{array}$} & \multirow[t]{2}{*}{-} & \multirow[t]{2}{*}{-} \\
\hline & $\begin{array}{l}\leftrightarrow \\
\text { Schlueter 2016 REM: } 4 \text { I }(-3,84) \\
\text { Siddiqui 2019: } 23.5(-5.9,67.8)\end{array}$ & & & \\
\hline \multirow[t]{2}{*}{$\begin{array}{l}\text { TIO/OLO } 5 / 5 \mu g \\
\text { OD }\end{array}$} & $\begin{array}{l}\uparrow \\
\text { Schlueter } 2016 \text { FEM: } 39(2,75) \\
\text { Sion 20I7: } 33.8(6.0,62.1)\end{array}$ & \multirow[t]{2}{*}{$\begin{array}{l}\leftrightarrow \\
\text { Siddiqui 2019: } 13.5(-11.1,43.3)\end{array}$} & \multirow{2}{*}{$\begin{array}{l}\leftrightarrow \\
\text { Aziz 2018: }-15.9(-62.2,30.5) \\
\text { Sion 20I7: }-9.7(-35.1,15.5) \\
\text { Schlueter 2016 FEM: }-3(-31,24) \\
\text { Schlueter 2016 REM: }-4(-42,-32) \\
\text { Siddiqui 2019: }-8.7(-46.7,18.6)\end{array}$} & \multirow[t]{2}{*}{-} \\
\hline & $\begin{array}{l}\leftrightarrow \\
\text { Aziz 20।8: } 27.6(-22.9,78.2) \\
\text { Schlueter 2016 REM: } 37(-11,82) \\
\text { Siddiqui 2019: } 14.0(-12.4,46.3)\end{array}$ & & & \\
\hline \multirow{6}{*}{$\begin{array}{l}\text { UMEC/VIL } 62.5 / 25 \\
\mu \mathrm{g} \text { OD }\end{array}$} & $\uparrow$ & \multirow{6}{*}{$\begin{array}{l}\leftrightarrow \\
\text { Siddiqui 2019: } 24.2(-2.8,54.6)\end{array}$} & \multirow{6}{*}{$\begin{array}{l}\leftrightarrow \\
\text { Aziz 20I8: 3.I (-27.9, 34.I) } \\
\text { Huisman 20I5: I4.I }(-14.2,42.3) \\
\text { Schlueter 2016 FEM: } 22(-7,50) \\
\text { Schlueter 2016 REM: } 20(-15,55) \\
\text { Siddiqui 2019: } 0.1(-33.6,29.8) \\
\text { Sion 20I7: 13.9 }(-13.0,41.3)\end{array}$} & \multirow{6}{*}{$\begin{array}{l}\leftrightarrow \\
\text { Aziz 20।8: } 18.9(-28.8,66.6) \\
\text { Schlueter } 2016 \text { FEM: } 25(-2,52) \\
\text { Schlueter 20।6 REM: } 24(-11,59) \\
\text { Siddiqui 2019: } 9.3(-13.9,36.8) \\
\text { Sion 20।7: } 23.7(-3.3,50.7)\end{array}$} \\
\hline & Aziz 20।8: $46.5(9.0,84.1)$ & & & \\
\hline & Schlueter 2016 FEM: $64(28,99)$ & & & \\
\hline & Schlueter 2016 REM: 61 ( $(8,103)$ & & & \\
\hline & Sion 2017: $57.5(28.8,87.1)$ & & & \\
\hline & $\begin{array}{l}\leftrightarrow \\
\text { Siddiqui 2019: } 24.5(-3.1,57.6)\end{array}$ & & & \\
\hline
\end{tabular}

Notes: ancluded as a primary or secondary endpoint in the studies included in the NMA. Siddiqui 2019 reports data for GLY/FOR I8/9.6 $\mu$ g vs other LAMA/LABAs FDCs. For completeness, comparisons between all LAMA/LABA FDCs in the NMA described in Siddiqui 2019 are provided in Supplementary Table 4 Results are presented as mean treatment difference in change from baseline, $\mathrm{mL}$ (Aziz et al reported $95 \% \mathrm{Cl}$, other studies reported $95 \% \mathrm{Crl}$ ). $\uparrow$ Statistically significantly favoring treatment $\mathrm{A}$ (light gray shading); $\leftrightarrow$ statistically non-significant (dark gray shading). All values from Schlueter 2016 converted from $L$ to $\mathrm{mL}$.

Abbreviations: $\mathrm{ACL}$, aclidinium; $\mathrm{BID}$, twice daily; $\mathrm{Cl}$, confidence interval; $\mathrm{Crl}$, credible interval; $\mathrm{FEV}$, forced expiratory volume in I second; $\mathrm{FEM}$, fixed-effects model; FOR, formoterol fumarate; GLY, glycopyrrolate; IND, indacaterol; NMA, network meta-analysis; OD, once daily; OLO, olodaterol; REM, random-effects model; TIO, tiotropium; UMEC, umeclidinium; VIL, vilanterol.

\section{Indirect Evidence: Safety}

The incidence of any AEs was analyzed in two NMAs, ${ }^{15,22}$ and discontinuations due to AEs were analyzed in one NMA. ${ }^{24}$ In these NMAs, the LAMA/LABA FDCs generally had comparable safety profiles with respect to these outcomes.

All-cause discontinuations were analyzed in two NMAs, ${ }^{15,24}$ with findings suggesting that the LAMA/ LABA FDCs evaluated were generally comparable; however, in the NMA by Schlueter et $\mathrm{al}^{24}$ a statistically significant difference in all-cause discontinuations at 24/26 weeks was observed in favor of tiotropium/olodaterol versus umeclidinium/vilanterol.

\section{Discussion}

Current treatment recommendations (GOLD 2020) for the use of LAMA/LABA FDCs in COPD provide guidance for the use of these agents as a class and do not differentiate between therapies within this class. ${ }^{4}$ These literature reviews were conducted to assess direct and indirect evidence for improvements in lung function, PROs, and safety with LAMA/LABA FDC therapies in patients with moderate-to-very severe airflow limitations in COPD.

From the review of direct evidence, it was apparent that few pairs of LAMA/LABA FDCs have been compared directly in head-to-head clinical trials. In total, only four RCTs were identified, all of which included 
umeclidinium/vilanterol as one of the treatments, and most of which focused primarily on lung function.

In terms of the primary endpoints, the non-inferiority of glycopyrrolate/formoterol fumarate versus umeclidinium/vilanterol was demonstrated in the AERISTO study for change from baseline in peak $\mathrm{FEV}_{1}$ but not trough $\mathrm{FEV}_{1}$ over 24 weeks. However, the lung function response with glycopyrrolate/formoterol fumarate in the AERISTO study was lower than that observed in previous studies of this combination. ${ }^{18}$ In Study A2349 and Study A2350, indacaterol/glycopyrrolate was not non-inferior to umeclidinium/vilanterol in change from baseline in $\mathrm{FEV}_{1}$ $\mathrm{AUC}_{0-24 \mathrm{~h}}$ at Week 12, which may have been due to the narrow non-inferiority margin of $-20 \mathrm{~mL} .{ }^{19}$ In Study GSK204990, umeclidinium/vilanterol was superior to tiotropium/olodaterol in change from baseline in trough $\mathrm{FEV}_{1}$ at Week $8 .^{20}$

Notable differences between the methodological and clinical characteristics were identified across the head-tohead studies included in the literature review. For example, study durations varied from 8 to 24 weeks, airflow limitation inclusion criteria varied from moderate only to moderate-to-very severe, and the blinding was different across the studies, such that AERISTO, Study A2349, and Study A2350 were double-blind trials while Study GSK204990 was an open-label trial (with an associated high risk of bias). Also, a non-inferiority margin of $50 \mathrm{~mL}$ was used for trough $\mathrm{FEV}_{1}$ in the AERISTO study and Study GSK204990, while the non-inferiority margin used for $\mathrm{FEV}_{1} \quad \mathrm{AUC}_{0-24 \mathrm{~h}}$ in the Kerwin et al ${ }^{19}$ studies (Study A2349 and Study A2350) was notably narrow (20 mL) and may have contributed to the failure to demonstrate non-inferiority. Moreover, the two studies that included glycopyrrolate/indacaterol as a treatment arm were conducted in the USA and administered the 15.6/27.5 $\mu \mathrm{g}$ twice-daily (BID) dose, ${ }^{19}$ which is only available in the USA. This inconsistency in the design of the head-to-head RCTs, as well as differences in the included patient population and endpoints reported and the inclusion of limited LAMA/LABA FDCs in these studies, some with a USonly dosing regimen, makes it difficult to draw generalizable, overarching conclusions regarding the comparative effectiveness of LAMA/LABA FDCs in patients with COPD from the direct comparisons alone.

With this scenario, a second literature review was undertaken to evaluate indirect evidence from NMAs, which allowed additional information on treatment comparisons to be obtained. NMAs allow direct and indirect evidence to be combined and, by linking data from RCTs through common treatment arms, allow trends in results across different trials to be assessed. ${ }^{26}$ Furthermore, NMAs have the potential to assess a greater variety of endpoints from a larger evidence base compared with the direct, head-to-head evidence. ${ }^{26}$

In contrast to the head-to-head RCTs, all five included NMAs identified in the literature search concluded that the different LAMA/LABA FDCs were generally comparable in terms of lung function improvements. Although certain statistically significant differences in trough and peak $\mathrm{FEV}_{1}$ were identified for some comparisons, the treatment differences were considered small, relative to established margins of clinical significance. ${ }^{27}$

Although $\mathrm{FEV}_{1}$ outcomes were the primary endpoints in all four head-to-head RCTs, it is known that airflow limitation is poorly related to other important clinical measures, such as symptoms and health status, due to the heterogeneous nature of COPD. ${ }^{28}$ The two key goals of COPD treatment, as outlined in the GOLD report, are to reduce symptoms and the future risk of exacerbations. ${ }^{4}$ Where assessed, the results of this review demonstrate that LAMA/LABA FDCs have comparable efficacy in improving symptoms, quality of life, and exacerbations when assessed in head-to-head studies. However, it should be noted that quality of life and symptoms were only assessed in two of the four head-to-head studies, ${ }^{18,20}$ and exacerbations were only assessed as an exploratory efficacy outcome in the AERISTO study. ${ }^{18}$ Moreover, none of the head-to-head studies assessed health status using SGRQ, a disease-specific health-related quality of life questionnaire. With respect to the indirect evidence, our review demonstrated that although the five included NMAs identified in the literature assessed different endpoints, investigation of endpoints that were not consistently reported in the head-to-head studies (TDI focal score, SGRQ, and exacerbations) was possible and enabled a greater number of LAMA/LABA FDCs to be compared. Consistent with the direct evidence, all NMAs identified in the literature search concluded that the different LAMA/LABA FDCs were generally comparable in terms of PROs and safety. ${ }^{15,22-25}$

While indirect evidence provides some additional information over head-to-head studies, it is important to note the inherent limitations of NMAs, such as concerns of bias, heterogeneity, precisions, and uncertainty in the estimated efficacies. ${ }^{26}$ It should be noted that only one of the five included NMAs (Siddiqui et $\mathrm{al}^{15}$ ) reported lung 
function outcomes other than trough $\mathrm{FEV}_{1}$, meaning that limited comparisons for lung function could be described in this literature review. Also, in the individual NMAs, very few studies could be included for the analyses of exacerbations, meaning there are high levels of uncertainty around these results.

In conclusion, from the systematic literature review, a limited number of head-to-head RCTs comparing LAMA/LABA FDCs in patients with COPD with moderate-to-very severe airflow limitation were identified. These head-to-head studies varied in design, endpoints, and baseline patient characteristics and evaluated a limited range of LAMA/LABA FDC comparisons. Additional information on the relative efficacy of LAMA/LABA FDCs was obtained from indirect comparisons in NMAs. Although there were some inconsistencies between the outcomes of the RCTs and NMAs for trough $\mathrm{FEV}_{1}$, the totality of lung function, symptoms, exacerbations, and safety data presented suggests that the available LAMA/LABA FDCs have comparable efficacy and safety in patients with COPD and moderate-to-severe airflow limitation. Given this, we suggest other factors such as patient preference and ability to use the device may be important when physicians are considering treatment choice within the class.

\section{Abbreviations}

AE, adverse event; AECOPD, acute exacerbations of chronic obstructive pulmonary disease; AUC, area under the plasma concentration-time curve; BID, twice daily; CAT, COPD Assessment Test; CI, confidence interval; CrI, credible interval; CSR, clinical study report; E-RS $\mathrm{COPD}_{\mathrm{C}}$, Evaluating Respiratory Symptoms COPD; FDC, fixed-dose combination; $\mathrm{FEV}_{1}$, forced expiratory volume in 1 second; FVC, forced vital capacity; GOLD, Global Initiative for Chronic Obstructive Lung Disease; IC, inspiratory capacity; ICS, inhaled corticosteroids; LABA, long-acting $\beta_{2}$-agonist; LAMA, long-acting muscarinic antagonist; LSM, least squares means; MDI, metered dose inhaler; NA, not applicable; NI, non-inferiority; NMA, network meta-analysis; NR, not reported; OD, once daily; PRO, patient-reported outcome; RCT, randomized controlled trial; SAMA, short-acting muscarinic antagonist; SE, standard error; SGA, subgroup analysis; SGRQ, St. George's Respiratory Questionnaire; TDI, Transition Dyspnea Index.

\section{Data Sharing Statement}

Not applicable.

\section{Ethics Approval and Consent}

Not applicable.

\section{Acknowledgments}

Medical writing support, under the direction of the authors, was provided by Karleen Nicholson, $\mathrm{PhD}$, on behalf of CMC Connect, and Jake Casson, PhD, CMC Connect, McCann Health Medical Communications, funded by AstraZeneca, Gaithersburg, USA in accordance with Good Publication Practice (GPP3) guidelines. ${ }^{29}$

\section{Author Contributions}

All authors made substantial contributions to conception and design, acquisition of data, or analysis and interpretation of data; took part in drafting the article or revising it critically for important intellectual content; gave final approval of the version to be published; and agree to be accountable for all aspects of the work.

\section{Funding}

This systematic review was conducted by Parexel International Ltd and funded by AstraZeneca. Employees of the sponsor were involved in various aspects of the conception and design of the studies, acquisition of data, analysis, and interpretation of data, and input into manuscript development. The sponsor did not place any restrictions on the authors about the statements made in the final article. No authors received payment for authorship.

\section{Disclosure}

JRH reports personal payments and payments to UCL for educational and advisory work and support to attend meetings, and grant support to UCL from pharmaceutical companies that make medicines to treat COPD, including AstraZeneca. KG-J has been a speaker for and consultant to AstraZeneca, Boehringer Ingelheim, GlaxoSmithKline, Mundipharma, Novartis, Pfizer, and Teva. During the conception and design of the study, KG-J was contracted to AstraZeneca and received a fee for services. MB, DG, MJ, and NS are employees of AstraZeneca and hold stock and/or stock options in the company. AB is an employee of Parexel International $\mathrm{Ltd}$, the organization that received funding from AstraZeneca to perform the systematic review. The authors report no other conflicts of interest in this work. 


\section{References}

1. GBD 2017 Causes of Death Collaborators. Global, regional, and national age-sex-specific mortality for 282 causes of death in 195 countries and territories, 1980-2017: a systematic analysis for the global burden of disease study 2017. Lancet. 2018;392 (10159):1736-1788.

2. GBD 2017 Disease and Injury Incidence and Prevalence Collaborators. Global, regional, and national incidence, prevalence, and years lived with disability for 354 diseases and injuries for 195 countries and territories, 1990-2017: a systematic analysis for the global burden of disease study 2017. Lancet. 2018;392 (10159):1789-1858.

3. World Health Organization. Chronic obstructive pulmonary disease (COPD) fact sheet; 2017. Available from: https://www.who.int/en/ news-room/fact-sheets/detail/chronic-obstructive-pulmonary-disease -(copd). Accessed December 21, 2017.

4. Global Initiative for Chronic Obstructive Lung Disease. 2020 report: global strategy for the diagnosis, management and prevention of COPD; 2020. Available from: https://goldcopd.org. Accessed March 17, 2020.

5. Bogart M, Stanford RH, Laliberté F, Germain G, Wu JW, Duh MS. Medication adherence and persistence in chronic obstructive pulmonary disease patients receiving triple therapy in a USA commercially insured population. Int J Chron Obstruct Pulmon Dis. 2019;14:343-352.

6. Yu AP, Guérin A. Ponce de Leon D, et al. Therapy persistence and adherence in patients with chronic obstructive pulmonary disease: multiple versus single long-acting maintenance inhalers. J Med Econ. 2011;14(4):486-496.

7. GlaxoSmithKline (Ireland) Limited. Anoro Ellipta summary of product characteristics; 2019. http://www.ema.europa.eu/docs/en_GB/ document_library/EPAR_-_Product_Information/human/002751/ WC500168424.pdf. Accessed April 11, 2019.

8. AstraZeneca AB Duaklir Genuair summary of product characteristics; 2017. http://www.ema.europa.eu/docs/en_GB/docu ment_library/EPAR_-_Product_Information/human/003745/ WC500178413.pdf. Accessed April 11, 2019.

9. Novartis Europharm Limited. Ultibro Breezhaler summary of product characteristics; 2017. http://www.ema.europa.eu/docs/en_GB/docu ment_library/EPAR_-_Product_Information/human/002679/ WC500151255.pdf. Accessed April 11, 2019.

10. Boehringer Ingelheim International GmbH. Spiolto Respimat summary of product characteristics; 2019. https://www.medicines.org.uk/ emc/product/6902. Accessed January 17, 2020.

11. AstraZeneca Pharmaceuticals LP Bevespi Aerosphere ${ }^{\mathrm{TM}}$ prescribing information; 2019. http://www.azpicentral.com/bevespi/bevespi_pi. pdf. Accessed July 2, 2019.

12. Usmani OS. Choosing the right inhaler for your asthma or COPD patient. Ther Clin Risk Manag. 2019;15(14):461-472.

13. Riley RD, Jackson D, Salanti G, et al. Multivariate and network meta-analysis of multiple outcomes and multiple treatments: rationale, concepts, and examples. BMJ. 2017;358:j3932.

14. Madan J, Stevenson MD, Cooper KL, Ades AE, Whyte S, Akehurst R. Consistency between direct and indirect trial evidence: is direct evidence always more reliable? Value Health. 2011;14 (6):953-960.

15. Siddiqui M, Shukla P, Jenkins M, et al. Systematic review and network meta-analysis of the efficacy and safety of glycopyrrolate/formoterol fumarate metered dose inhaler in comparison with other long-acting muscarinic antagonist/long-acting $\beta_{2}$-agonist fixed-dose combinations in COPD. Ther Adv Respir Dis. 2019;13:17534 66619894502 .
16. Jansen JP, Trikalinos T, Cappelleri JC, et al. Indirect treatment comparison/network meta-analysis study questionnaire to assess relevance and credibility to inform health care decision making: an ISPOR-AMCP-NPC good practice task force report. Value Health. 2014;17(2):157-173.

17. European Medicines Agency. Guideline on the clinical investigation of medicinal products for the treatment of chronic obstructive pulmonary disease (COPD); 2012. Available from: https://www.ema. europa.eu/en/documents/scientific-guideline/guideline-clinicalinvestigation-medicinal-products-treatment-chronic-obstructivepulmonary-disease_en.pdf. Accessed March 25, 2019.

18. Maltais F, Ferguson GT, Feldman GJ, et al. A randomized, double-blind, double-dummy study of glycopyrrolate/formoterol fumarate metered dose inhaler relative to umeclidinium/vilanterol dry powder inhaler in COPD. Adv Ther. 2019;36(9):2434-2449.

19. Kerwin E, Ferguson GT, Sanjar S, et al. Dual bronchodilation with indacaterol maleate/glycopyrronium bromide compared with umeclidinium bromide/vilanterol in patients with moderate-to-severe COPD: results from two randomized, controlled, cross-over studies. Lung. 2017;195(6):739-747.

20. Feldman GJ, Sousa AR, Lipson DA, et al. Comparative efficacy of once-daily umeclidinium/vilanterol and tiotropium/olodaterol therapy in symptomatic chronic obstructive pulmonary disease: a randomized study. Adv Ther. 2017;34(11):2518-2533.

21. Rogliani P, Matera MG, Ritondo BL, et al. Efficacy and cardiovascular safety profile of dual bronchodilation therapy in chronic obstructive pulmonary disease: A bidimensional comparative analysis across fixed-dose combinations. Pulm Pharmacol Ther. 2019;59:101841.

22. Aziz MIA, Tan LE, Wu DB, et al. Comparative efficacy of inhaled medications (ICS/LABA, LAMA, LAMA/LABA and SAMA) for COPD: a systematic review and network meta-analysis. Int $J$ Chron Obstruct Pulmon Dis. 2018;13:3203-3231.

23. Sion KYJ, Huisman EL, Punekar YS, Naya I, Ismaila AS. A network meta-analysis of long-acting muscarinic antagonist (LAMA) and long-acting $\beta 2$-agonist (LABA) combinations in COPD. Pulm Ther. 2017;3(2):297-316.

24. Schlueter M, Gonzalez-Rojas N, Baldwin M, Groenke L, Voss F, Reason T. Comparative efficacy of fixed-dose combinations of longacting muscarinic antagonists and long-acting $\beta 2$-agonists: a systematic review and network meta-analysis. Ther Adv Respir Dis. 2016;10(2):89-104.

25. Huisman EL, Cockle SM, Ismaila AS, Karabis A, Punekar YS. Comparative efficacy of combination bronchodilator therapies in COPD: a network meta-analysis. Int J Chron Obstruct Pulmon Dis. 2015;10:1863-1881.

26. Tonin FS, Rotta I, Mendes AM, Pontarolo R. Network meta-analysis: a technique to gather evidence from direct and indirect comparisons. Pharm Pract. 2017;15(1):943.

27. Jones PW, Beeh KM, Chapman KR, Decramer M, Mahler DA, Wedzicha JA. Minimal clinically important differences in pharmacological trials. Am J Respir Crit Care Med. 2014;189(3):250-255.

28. Agusti A, Calverley PM, Celli B, et al. Characterisation of COPD heterogeneity in the ECLIPSE cohort. Respir Res. 2010;11:122.

29. Battisti WP, Wager E, Baltzer L, et al. Good publication practice for communicating company-sponsored medical research: GPP3. Ann Intern Med. 2015;163(6):461-464. 


\section{Publish your work in this journal}

The International Journal of COPD is an international, peer-reviewed journal of therapeutics and pharmacology focusing on concise rapid reporting of clinical studies and reviews in COPD. Special focus is given to the pathophysiological processes underlying the disease, intervention programs, patient focused education, and self management protocols. This journal is indexed on PubMed Central, MedLine and CAS. The manuscript management system is completely online and includes a very quick and fair peer-review system, which is all easy to use. Visit http://www.dovepress.com/testimonials.php to read real quotes from published authors. 